\title{
The Efficacy of Serum Biomarkers and Ultrasound Parameters in Prediction of Outcome in Threatened Abortion
}

\author{
Hanaa Omer Badr El Dien, Asmaa Mahmoud Abd Elwahab, Eman Mostafa Abdalla* \\ Department of Obstetrics and Gynecology, of Medicine, Al-Azhar University \\ *Correspondence author: Eman Mostafa Abdalla, Mobile: (+20)01060970951, E-mail: Emanm5387@gmail.com
}

\begin{abstract}
Background: miscarriage, also known as a spontaneous loss of pregnancy before the fetus reaches viability. Objectives: the aim of this study is to evaluate the association between ultrasonographic findings and maternal serum biomarkers levels and prediction of pregnancy outcome in threatened miscarriage. Patients and Methods: a prospective observational study was conducted at Al-Zahraa University Hospital through the period from April 2018 to May 2019 involving 76 women in their first trimester threatened abortion. Results: there was a statistically significant difference between group 1 and group 2 regarding cancer antigen (CA) 125, $\beta$-hCG, progesterone, yolk sac diameter (YSD), fetal heart rate (FHR) and crown-rump length (CRL). The sensitivity, specificity, PPV and NPV of CA 125 at $37.2 \mathrm{IU} / \mathrm{ml}$ were 86.0, 84.3, 84.6 and 85.7, respectively, for $\beta$-hCG at $19447 \mathrm{IU} / \mathrm{ml}$ were 80.6, 78.0, 78.4 and 79.8, respectively, for progesterone at $12.3 \mathrm{ng} / \mathrm{ml}$ were $90.1,88.0,88.2$ and 89.8, respectively, and for FHR at $122 \mathrm{~b}$ pm were 96.1, 94.1 respectively.
\end{abstract}

Conclusion: combining of measurement of serum progesterone at a level of $12.3 \mathrm{ng} / \mathrm{ml}$ to FHR at $122 \mathrm{bpm}$ represent noninvasive, early, fast and excellent predictor of pregnancy outcome in women with threatened abortion.

Keywords: CA125; $\beta$-hCG, Progesterone; Fetal heart rate, CRL, GSD, YSD, Threatened abortion.

\section{INTRODUCTION}

Miscarriage is a spontaneous loss of pregnancy before the fetus reaches viability, miscarriage is defined as the loss of a pregnancy before 24 weeks of gestation in the UK. The National Center for Health Statistics, the Centers for Disease Control and Prevention and the World Health Organization define abortion as termination of pregnancy before 20 weeks of gestation or with a fetus of less than $500 \mathrm{~g}^{(\mathbf{1})}$.

Miscarriage is a physically and mentally traumatic event that frequently has long-term psychological consequences. Every effort should therefore be made to maintain viable pregnancies in women with threatened miscarriage. Our understanding of pregnancy has advanced considerably in recent years, and the quality of much of the evidence available regarding the efficacy and safety of the various treatment options is not in line with current standards ${ }^{(2)}$.

Ultrasound consider the backbone of modern obstetrics and gynecology practice. Its examination has become the "golden standard" in follow-up of the development and complications of early pregnancy. Many sonographic markers in early pregnancy can predict the prognosis of the outcome of pregnancy; these include gestational sac diameter (GSD), yolk sac diameter (YSD), crown-rump length (CRL), and fetal heart rate (FHR), which were considered as one of the main parameters for the prediction of outcome of pregnancy ${ }^{(3)}$. Threatened miscarriage affects one fifth of women, with the uncertainty about its prognosis, and many biochemical markers have been studied to predict its outcome. Various biochemical markers have been studied to establish if they are able to predict the outcome of threatened miscarriage (i.e. identify those at risk of subsequent miscarriage), however results have been conflicting. Some of the commonly studied biochemical markers are serum human chorionic gonadotropin (hCG), progesterone, cancer antigen 125
(CA 125), pregnancy associated plasma protein A (PAPP-A), human placental lactogen (HPL), alpha fetoprotein (AFP), inhibin A and activin $\mathrm{A}^{(4)}$.

Progesterone production in early pregnancy reflects the interaction between the trophoblast and corpus luteum. There is positive association between the rise in serum $\beta$-hCG and progesterone production by the corpus luteum. It was shown that the spontaneous pregnancy failure decreases with increasing maternal serum progesterone levels ${ }^{(5)}$.

\section{AIM OF THE WORK}

The aim of this study is to evaluate the association between ultrasonographic findings and maternal serum biomarkers (progesterone, $\beta$-hCG and cancer antigen125 ) levels to predict pregnancy outcome in threatened miscarriage.

\section{PATIENTS AND METHODS}

This prospective observational study was held in the period from April 2018 to May 2019 on 76 pregnant patients who attended the Outpatient Clinic or the Emergency Department. Ethical approval and Written informed consent:

An approval of the study was obtained from AlAzhar University academic and ethical committee. Every patient signed an informed written consent for acceptance of the procedure.

Our study included 76 pregnant patients attended the Outpatient Clinic or The Emergency Department of Obstetrics and Gynecology from April 2018 to May 2019, at Al-Zahraa University Hospital complaining of uterine bleeding or bloody vaginal discharge and / or lower abdominal pain.

Women included in the present study were diagnosed as first trimester threatened miscarriage, presenting with uterine bleeding or spotting, mild or no pain, had singleton spontaneous pregnancy, and pregnancy was between $7^{\text {th }}$ and $13^{\text {th }}$ week of gestational 
age. Gestational age was calculated at the time of recruitment according to first day of last menstrual period and was confirmed by transvaginal ultrasound examination. The maternal age ranged between 24-43 years. Women with multiple gestation, missed abortion (delayed abortion), blighted ovum, inevitable or incomplete abortion, ectopic pregnancy or gestational trophoblastic disease, patients with history of general medical disease e.g. diabetes or thyroid disease, presence of local (gynecological) disease e.g. fibroid or adnexal masses verified by normal appearance of the uterus and ovaries by ultrasound, and patients with history of recurrent miscarriages were excluded from the study. All patients were subjected to the following: full history taking including, personal history, present history, obstetric history, and menstrual history.

All patients were subjected to general examination; including vital signs: pulse, blood pressure and temperature and body mass index (weight in $\mathrm{Kg} / \mathrm{m}^{2}$ ). General examination also included upper and lower limps, chest, heart and abdominal examination. Local pelvic examination including: Inspection of the perineum for amount of bleeding, signs of trauma or lesions to detect any abnormalities, infections or ulcer. Bimanual examination and estimation of uterine size, shape, position, and consistency; examination of the adnexa for masses or tenderness. Speculum examination to: localize the bleeding origin: vagina, cervix, uterus; quantify the bleeding; inspect the cervix for presence of polyps, ulcers or other lesions.

Routine antenatal investigations (complete blood count, cytomegalovirus antibodies, $\mathrm{Rh} \mathrm{ABO}$, rubella antibodies, hepatitis B surface antigen, fasting and postprandial blood sugar and complete urine analysis).

Ultrasound examination included ultrasound examinations of this study were done and reviewed by obstetric sonography. Logiq-5 Sonography Machine from GE was used for sonographic evaluation. All women were examined by transvaginal two dimensional ultrasound to confirm intrauterine pregnancy, assessment of FHR, gestational sac (GS) and yolk sac (YS), presence/absence of sub-chorionic hematoma.

Biochemical studies $5 \mathrm{ml}$ venous blood samples were collected at admission from all participants then centrifugation for analysis then measurement of maternal serum CA-125 levels, serum progesterone levels and serum $\beta$-hCG levels was performed by quantitative ELISA (enzyme linked immunoassay)

Follow up of patients was carried out until they passed into second trimester weeks of pregnancy, and patients from the study group were subdivided into: group of patients who aborted and group who continued their pregnancy and proceeded into the second trimester.

Then, Comparison was done between the two study groups; regarding ultrasound findings and biochemical markers levels for predicting the outcome of firsttrimester threatened abortion.

\section{Statistical analysis}

Recorded data were analyzed using the statistical package for social sciences, version 20.0 (SPSS Inc., Chicago, Illinois, USA). Quantitative data were expressed as mean \pm standard deviation (SD). Qualitative data were expressed as frequency and percentage.

\section{The following tests were done:}

- Independent-samples t-test of significance was used when comparing between two means.

- Chi-square $\left(\mathrm{x}^{2}\right)$ test of significance was used in order to compare proportions between two qualitative parameters.

- The confidence interval was set to $95 \%$ and the margin of error accepted was set to $5 \%$. The pvalue was considered significant as the following:

- Probability (P-value)

- P-value <0.05 was considered significant.

- P-value <0.001 was considered as highly significant.

- P-value >0.05 was considered insignificant.

\section{RESULTS}

Women included in this study were divided into two groups: group (GI) including patients who aborted (17 patients) and group (GII) including patients who continued their pregnancy and proceeded into the second trimester (59 patients).

There was significant difference between the two groups of the study as regard age and BMI while there was significant difference between the two groups of the study regarding gestational age, parity and gravidity (table

Table (1): Comparison between group I and group II: according to demographic data.

\begin{tabular}{|c|c|c|c|c|}
\hline & $\begin{array}{l}\text { Baseline } \\
\text { characteristics }\end{array}$ & Group I: Aborted $(n=17)$ & Group II: Continue $(n=59)$ & p-value \\
\hline Age (years) & $\begin{array}{l}\text { Mean } \pm \text { SD } \\
\text { Range }\end{array}$ & $\begin{array}{c}36.71 \pm 6.04 \\
24-44\end{array}$ & $\begin{array}{c}31.97 \pm 5.13 \\
26-40\end{array}$ & $<0.002 *$ \\
\hline BMI & $\begin{array}{l}\text { Mean } \pm \text { SD } \\
\text { Range }\end{array}$ & $\begin{array}{c}29.41 \pm 2.69 \\
26-35\end{array}$ & $\begin{array}{c}26.83 \pm 2.84 \\
24-30\end{array}$ & $<0.002^{*}$ \\
\hline $\begin{array}{l}\text { Gestional } \\
\text { age (weeks) }\end{array}$ & $\begin{array}{l}\text { Mean } \pm \text { SD } \\
\text { Range }\end{array}$ & $\begin{array}{c}7.85 \pm 0.76 \\
7-9\end{array}$ & $\begin{array}{c}8.17 \pm 1.00 \\
7-10.3\end{array}$ & 0.236 \\
\hline Gravidity & $\begin{array}{l}\text { Mean } \pm \text { SD } \\
\text { Range }\end{array}$ & $\begin{array}{c}2.65 \pm 1.27 \\
1-4\end{array}$ & $\begin{array}{c}2.41 \pm 1.07 \\
1-6\end{array}$ & 0.437 \\
\hline Parity & $\begin{array}{l}\text { Mean } \pm \text { SD } \\
\text { Range }\end{array}$ & $\begin{array}{c}1.29 \pm 0.92 \\
0-3\end{array}$ & $\begin{array}{c}1.17 \pm 0.87 \\
0-3\end{array}$ & 0.610 \\
\hline
\end{tabular}

p-value $>0.05 \mathrm{NS} ;{ }^{*}$-value $<0.05 \mathrm{~S}$ 
The study of ultrasonographic markers reported a statistically significant difference between the two groups of the study regarding gestational sac diameter, yolk sac diameter, fetal heart rate and CRL (Table 2). There was no a statistically significant difference between the two groups regarding sub chorionic hematoma (Table 2).

Table (2): Comparison between group I and group II according to ultrasonographic findings to predict pregnancy outcome among patients presented with threatened abortion during first trimester.

\begin{tabular}{|l|c|c|c|}
\hline Ultrasonographic & Group I: Aborted $(\boldsymbol{n}=\mathbf{1 7})$ & Group II: Continue $(\boldsymbol{n}=\mathbf{5 9})$ & p-value \\
\hline GSD & $29.76 \pm 5.79$ & $34.71 \pm 7.39$ & \\
Mean \pm SD & $23.5-39$ & $22-50$ & $0.013^{*}$ \\
Range & $13.38 \pm 4.47$ & $17.91 \pm 7.09$ & \\
\hline CRL & $8-20$ & $9-35$ & $0.015^{*}$ \\
Mean \pm SD & $104.35 \pm 5.31$ & $167.58 \pm 15.10$ & \\
Range & $98-112$ & $102-185$ & $<0.001^{* *}$ \\
\hline FHR (bpm) & & & \\
Mean \pm SD & $2.94 \pm 0.26$ & $4.39 \pm 0.98$ & $0.001^{*}$ \\
Range & $2.5-3.5$ & $2.6-6$ & \\
\hline $\begin{array}{l}\text { Yolk sac diameter } \\
\text { Mean } \pm \text { SD }\end{array}$ & $9(52.9 \%)$ & $41(69.5 \%)$ & 0.176 \\
Rang & $8(47.1 \%)$ & $18(30.5 \%)$ & \\
\hline Hematoma & & & \\
Absent & & & \\
Present & & & \\
\hline
\end{tabular}

*p-value $<0.05 \mathrm{~S} ; * *$ p-value $<0.001$,

The study of biochemical markers revealed a statistically significant difference between the two groups as regard serum CA 125 levels, $\square$-hCG levels and serum progesterone levels (Table 3).

Table (3): Comparison between group I and group II according to biochemical markers levels for prediction of pregnancy outcome.

\begin{tabular}{|l|c|c|c|}
\hline Biochemical & Group I: Aborted $(\boldsymbol{n}=\mathbf{1 7})$ & Group II: Continue $(\boldsymbol{n}=\mathbf{5 9})$ & p-value \\
\hline CA125 $($ Mean \pm SD) & $68.05 \pm 8.71$ & $26.36 \pm 1.29$ & $<0.001^{* *}$ \\
\hline $\begin{array}{l}\text { Serum progesterone }(\mathrm{ng} / \mathrm{ml}) \\
\text { Mean } \pm \text { SD }\end{array}$ & $9.81 \pm 1.72$ & $23.27 \pm 3.28$ & $<0.001^{* *}$ \\
\hline $\begin{array}{l}\square-h C G \\
\text { Mean } \pm \text { SD }\end{array}$ & $12.68 \pm 2.60$ & $71.13 \pm 5.21$ & $<0.001^{* *}$ \\
\hline
\end{tabular}

$* *$ p-value <0.001 HS

Table 4 reported the sensitivity, specificity, PPV and NPV of significant predictors as fetal heart rate at $112 \mathrm{bpm}$, GSD at $39 \mathrm{~mm}$, CRL at $9 \mathrm{~mm}, \mathrm{CA} 125$ at the level of $37.2 \mathrm{IU} / \mathrm{ml}, \beta-\mathrm{hCG}$ at the level of $19487 \mathrm{mIU} / \mathrm{ml}$ and progesterone at the level of $12.3 \mathrm{ng} / \mathrm{ml}$.

Table (4): The sensitivity, specificity, PPV and NPV in prediction of aborted using the ultrasonographic and biochemical

\begin{tabular}{|l|c|c|c|c|c|}
\hline Items & Cut-off & Sen. & Spe. & PPV & NPV \\
\hline Ultrasonographic & & & & & \\
\hline GSD & $<\mathbf{3 9}$ & $52.0 \%$ & $50.0 \%$ & $51.0 \%$ & $51.0 \%$ \\
\hline CRL & $<9$ & $60.0 \%$ & $58.0 \%$ & $58.8 \%$ & $59.2 \%$ \\
\hline FHR & $<\mathbf{1 2 2}$ & $96.0 \%$ & $94.0 \%$ & $94.1 \%$ & $95.9 \%$ \\
\hline Yolk sac diameter & $<\mathbf{3}$ & $56.0 \%$ & $50.0 \%$ & $52.8 \%$ & $53.2 \%$ \\
\hline Biochemical & & & & & \\
\hline CA125 & $>\mathbf{3 7 . 2}$ & $86.0 \%$ & $84.0 \%$ & $84.3 \%$ & $85.7 \%$ \\
\hline Serum progesterone & $<\mathbf{1 2 . 3}$ & $90.0 \%$ & $88.0 \%$ & $88.2 \%$ & $89.8 \%$ \\
\hline$\beta$-hCG & $<\mathbf{1 9 . 4}$ & $80.0 \%$ & $78.0 \%$ & $78.4 \%$ & $79.6 \%$ \\
\hline
\end{tabular}

\section{DISCUSSION}

Miscarriage refers to a spontaneous loss of pregnancy before the fetus reaches viability. In the United Kingdom, miscarriage is defined as the loss of a pregnancy before 24 weeks of gestation. After 24 completed weeks, pregnancy loss is legally defined as stillbirth $^{(\mathbf{6})}$. 
Moreover; clinical miscarriage is both a common and distressing complications of early pregnancy which had physical and psychological impact on both partners and doctors, which may be immediate or long term effect. About $48.8 \%$ of women facing threatened miscarriage are at high risk for clinical anxiety and depressive symptoms and had adverse impacts on maternal wellbeing ${ }^{(7)}$.

The aim of this study is to evaluate the association between ultrasonographic findings and maternal serum biomarkers (progesterone, $\beta$-hCG and cancer antigen 125) levels in threatened miscarriage to predict pregnancy outcome.

In our study there was a statistically significant difference regarding mean maternal age between group 1 (GI) who were diagnosed as threatened abortion and ended by abortion and group 2 (GII) who were diagnosed as threatened abortion and their pregnancy proceeded into the second trimester and this is in agreement with the study of Mbugua et $\boldsymbol{a l} .{ }^{(8)}$; who reported that advancing maternal age is associated with an increased risk of miscarriage. However, these results are not in agreement with the study of Dadkhah $\boldsymbol{e t}$ al. (9); who did not have any significant differences according to maternal age in women with advanced maternal age on evaluation of the pregnancy outcome in cases with threatened miscarriage

Our study showed that obesity was associated with a significant increase in early pregnancy losses. These results are in agreement with Metwally et al. ${ }^{(10)}$; who reported that increase body mass index is associated with an increased risk of first trimester miscarriage and women with BMI $>25 \mathrm{~kg} / \mathrm{m}^{2}$ had significantly higher risk of miscarriage. However, these results are not in agreement with Hornberger $\boldsymbol{e t}$ al. ${ }^{(11)}$ who concluded that maternal obesity did not correlate with spontaneous early pregnancy loss

Regarding ultrasound finding among patients with threatened abortion in predicting early pregnancy outcome, gestational sac diameter (GSD) in our study showed significant association between GSD and subsequent fetal loss between two groups.

These results are in agreement with the study of $\mathbf{A l}$ Mohamady et al. ${ }^{(12)}$, who evaluated the outcome of pregnancies with first trimester threatened abortion and reported a significant association between a small and abnormal GSD and subsequent fetal loss

However, these results are not in agreement with the study by $\mathbf{O h}$ et $\boldsymbol{a l} .{ }^{(\mathbf{1 3})}$, who did not find association between GSD and early pregnancy outcome in patients with threatened abortion.

In our study as regard CRL, there was a statistically significant difference between GI and GII. Our findings agreed with Abuelghar et al. ${ }^{(14)}$ who found that $56.6 \%$ of women who experienced abortion had CRL below the $5^{\text {th }}$ percentile with a sensitivity of $56.6 \%$ and specificity of $81.9 \%$ and a smaller than expected CRL reliably predict the occurrence of subsequent miscarriage in first trimester threatened abortion
On the other hand, our results are not in agreement with Nibras et al. ${ }^{(15)}$, who reported that a smaller than expected crown to rump length for gestational age is not a prognostic factor for prediction of abortion in women presented with threatened miscarriage

Our study found that there is a significant association between abnormal yolk sac diameter $(<3$ or $>6$ ) and miscarriage. These results are consistent with Sanam et al. ${ }^{(16)}$ who reported that yolk sac diameter less than $2 \mathrm{~mm}$ or greater than $5 \mathrm{~mm}$ are at more risk of spontaneous miscarriage. On the other hand Makrydimas et al. ${ }^{(17)}$ in their study did not find significant association between abnormal yolk sac diameter and fetal loss.

In our study, we reported that the FHR was highly significantly different between GI and GII and there was a good association between decrease of FHR and miscarriage. Our results are in agreement with Papaioannou et al. ${ }^{(18)}$; who reported that a low fetal heart rate was associated with an increased risk of first trimester miscarriage

Our present study revealed that the presence of $\mathrm{SCH}$ in patients with threatened abortion did not increases the risk of miscarriage in early pregnancy. These results are in agreement with Ben-Haroush et al. ${ }^{(19)}$, they reported that size of $\mathrm{SCH}$, and duration of bleeding did not affect the pregnancy outcome. On other hand, these results did not agree with Soldo et al. (20) who reported that intrauterine hematomas are associated with higher miscarriage rate

In the current study we evaluated the possible role of serum CA125 measurement in the prognosis of first trimester pregnancy among patients presented with threatened abortion. Serum CA125 levels were higher in GI mean who aborted and decrease in GII who proceed into second trimester with $\mathrm{p}$ value of $<0.001$. These results are consistent with study of Pillai $\boldsymbol{e t} \boldsymbol{a l}$. (4), who revealed a significant role of CA 125 levels in the prediction of outcome in women with threatened miscarriage. However Mahdi ${ }^{(21)}$, who revealed that measurement of CA125 levels is not of value to predict the outcome of threatened abortion because it is secreted from different origin.

Our study revealed that a low levels of $\beta$-hCG predict a higher risk of miscarriage and used in the determination of the prediction of outcome among patients with threatened abortion. This was in agreement with the study of Osmanağaoğlu et $\boldsymbol{a l} .{ }^{(22)}$ who concluded that the single measurement of serum $\beta$-hCG levels can be useful in the prediction of first trimester spontaneous abortions.

Our study reported that serum progesterone had a good role in the prediction of first trimester abortion. Serum progesterone levels were higher in group II who proceed into second trimester than GI mean who aborted. The result of this study is in agreement with Altay et al. ${ }^{(23)}$; who concluded that serum progesterone could predict women with low risk miscarriage at $10^{\text {th }}$ week of pregnancy. On the other hand, Darwish et al. (24) reported that progesterone is not significant in the 
prediction of pregnancy outcome in cases with first trimester pregnancy loss.

\section{CONCLUSION AND RECOMMENDATIONS}

Reliable and early prediction of abortion in the first trimester could potentially improve pregnancy outcomes because it would allow closer prenatal monitoring, earlier diagnosis, and expeditious interventions.

Combining of measurement of serum progesterone at a level of $12.3 \mathrm{ng} / \mathrm{ml}$ to FHR at $122 \mathrm{bpm}$ represent non-invasive, early, fast and excellent predictor of pregnancy outcome in women with threatened abortion and can decrease the anxiety of both the patient and doctor.

\section{REFERENCES}

1. Lawn JE, Blencowe $H$, Waiswa $P$ et al. (2016): Stillbirths: rates, risk factors, and acceleration towards 2030. The Lancet, 387: 587-603.

2. Bailey SL, Jacky B, Ying C et al. (2019): Hope for the best... but expect the worst: a qualitative study to explore how women with recurrent miscarriage experience the early waiting period of a new pregnancy. BMJ Open, 9.5: e029354.

3. Al Darwish AG, Fouad M, Nasr A et al. (2019): Early ultrasound fetal parameters as a predictor for pregnancy outcome: A prospective observational cohort study." Gyne and Obste Open A Open J., 1: 7-12

4. Pillai RN, Konje JC, Tincello DG et al. (2016): Role of serum biomarkers in the prediction of outcome in women with threatened miscarriage: a systematic review and diagnostic accuracy meta-analysis. Human reproduction update, 22: 228-239.

5. Pundir J and Arri C (2016): Gynaecology: evidencebased algorithms. Cambridge University Press, 2016. https://doi.org/10.1017/CBO9781316156513

6. Lewis MS (2016): Criminalizing substance abuse and undermining Roe V. Wade: The tension between abortion doctrine and the criminalization of prenatal substance abuse.

scholarship.law.wm.edu/cgi/viewcontent.cgi?article $=144$ $6 \&$ context=wmjowl

7. Zhu CS, Tan TC, Chen HY et al. (2018): Threatened miscarriage and depressive and anxiety symptoms among women and partners in early pregnancy. Journal of Affective Disorders, 237: 1-9.

8. Mbugua GG, Liversedge H, Goffey D et al. (2009): The influence of maternal age on the outcomes of pregnancies complicated by bleeding at less than 12 weeks. Acta Obstet Gynecol Scand., 88:116-8.

9. Dadkhah F, Kashanian $M$ and Giuti E (2010): A comparison between the pregnancy outcome in women both with or without threatened abortion. Early Human Development, 86: 193-196.

10. Metwally M, Ong KJ, Ledger WL et al. (2008): Does high body mass index increase the risk of miscarriage after spontaneous and assisted conception? A metaanalysis of the evidence. Fertil Steril., 90(3):714-26.

11. Hornberger AB, King A, Bachman $N$ et al. (2017): Katz-Jaffe Maternal Obesity is not associated with increased miscarriage rates following euploid blastocyst transfer. https://cfas.ca/thursday-posters.html

12. Al Mohamady M, Abdel Fattah G, Ahmed DH (2016): Correlation of serum CA-125 and progesterone levels with ultrasound markers in the prediction of pregnancy outcome in threatened miscarriage. International Journal of Fertility \& Sterility, 9: 506-509.

13. Oh JS, Wright G, Coulam CB (2002): Gestational sac diameter in very early pregnancy as a predictor of fetal outcome. Ultrasound in Obstetrics and Gynecology, 20: 267-269.

14. Abuelghar F, Ellaithy MI, Anwar MA (2013): Can a smaller than expected crown-rump length reliably predict the occurrence of subsequent miscarriage in a viable first trimester pregnancy?. Journal of Obstetrics and Gynaecology Research, 39: 1449-1455.

15. Nibras J, Mohammed N, Ismail WA et al. (2017): Predictors of poor first trimester outcome in asymptomatic women: the value of embryonic heart rate, mid sac diameter/yolk sac ratio \& mid sac diameter/crown rump length." Al-Kindy College Medical Journal, 13: 46-50.

16. Sanam $M$ and Mohammad $F$ (2012): Are abnormal yolk sac characteristics important factors in abortion rates?. International Journal of Fertility \& Sterility, 6: $127-132$

17. Makrydimas G, Sebire NJ, Lolis D et al. (2003): Fetal loss following ultrasound diagnosis of a live fetus at 6-10 weeks of gestation. International Society of Ultrasound in Obstetrics and Gynecology, 22: 368-372.

18. Papaioannou G, Syngelaki A, Maiz N et al. (2011): Ultrasonographic prediction of early miscarriage. Hum Reprod., 26(7): 1685-1692.

19. Ben-Haroush A, Yogev Y, Mashiach R et al. (2003): Pregnancy outcome of threatened abortion with subchorionic hematoma: possible benefit of bedrest?. Imaj-Ramat Gan., 5: 422-424.

20. Soldo V, Cutura N, Zamurovic M (2013): Threatened miscarriage in the first trimester and retrochorial hematomas: sonographic evaluation and significance. Clin Exp Obstet Gynecol., 40(4):548-50.

21. Mahdi BM (2012): Role of tumor marker CA125 in the detection of spontaneous abortion from preconception to postpartum. http://www.intechopen.com/books/frompreconception-to-postpartum/role-of-tumor-marker-ca125-indetection-spontaneous-abortion

22. Osmanağaoğlu M, Erdoğan İ, Eminağaoğlu $\mathrm{S}$ et al. (2010): The diagnostic value of $\beta$-human chorionic gonadotropin, progesterone, CA125 in the prediction of abortions. Journal of Obstetrics and Gynaecology, 30: 288-293.

23. Altay M, Özkaya E, Gelisen O et al. (2011): Significance of subchorionic haemorrhage and pregnancy outcome in threatened miscarriage to predict miscarriage, pre-term labour and intrauterine growth restriction. J Obstet Gynaecol., 31:210-2.

24. Darwish A, Ghorab N, Hazem E et al. (2005): Biochemical markers for prediction of pregnancy outcome incases of recurrent pregnancy loss. Middle East Fertil Soc., 10:59-62. 